\title{
The Difference of Mental Skills in Superior Basketball Players and Gymnasts with Different Levels of Experience
}

\author{
Mohammad Maleki, Sardar Mohammadi, Ali Nazarian \\ University of Kurdistan, Sanandaj, Iran \\ Email: mohammad maleki100@yahoo.com
}

Received 4 June 2014; revised 12 July 2014; accepted 14 August 2014

Copyright (C) 2014 by authors and OALib.

This work is licensed under the Creative Commons Attribution International License (CC BY). http://creativecommons.org/licenses/by/4.0/

(c) †) Open Access

\section{Abstract}

This study aimed to compare mental skills between superior basketball players and gymnasts. Subjects included 161 basketball players (91 experienced: aged $22.47 \pm 2.27$, and 70 inexperienced, aged $23.13 \pm 2.2$ ) and 114 gymnasts (66 experienced; aged $22.77 \pm 2.03$ and 48 inexperienced, aged $22.79 \pm 2.25$ ). The questionnaire used for this study was OMSAT-3 that assessed mental skills in three main categories of foundation mental skills, psychosomatic skills and cognitive skills. Results showed significant differences between elite and sub-elite basketball players and gymnasts in basic mental skills, psychosomatic skills and cognitive skills. These results will help coaches and athletes to improve their performance and consolidate and expand the use of mental skills they need for each competition in closed and open sport skills.

\section{Keywords}

Mental Skills, Basketball, Gymnasts, Experience

Subject Areas: Psychology, Sports Science

\section{Introduction}

Although athletes' physical fitness and the kind of techniques they use can affect their performance to a great extent, mental preparation can also affect a sport player's performance tremendously [1]. Mental preparation and perceived mental skills [2] are essential requirements for continuous peak performance. To this end, researchers believe that the following factors affect athletes' performance: commitment, quality of exercise, concentration, refocusing in competition, using mental imagery, goal setting, activation, competition planning, high self-confidence, controlling anxiety, and positive attitude [3].

In recent years, there has been an increasing interest in examining direct or opposite relation between mental 
skill and performance level in various sport fields [4]. One of the most significant current discussions in sport psychology is that mental skills in team and individual sports are different for the athletes in each field [5]. Depending on the different physical and technical characteristics, amount of reliance on their abilities and interactions with teammates, athletes experience unique factors affecting their exercise and competition. Some researchers believe that athletes in individual sports must have a rather higher level of mental preparation in comparison with team-sport athletes, since they must rely on their own abilities during a sport context, rather than getting help from teammates [6]. Athletes in various sports receive different stimulations and responses, thus have their own different interpretation of mental skills. Therefore, mental skills used by athletes of open sports are not necessarily similar to skills that might be used by athletes of closed sports [7], because in such sports the athlete's motor pattern is constant compared with environmental features, which enables them to perform more effectively in exercise and competition [4]. The most important mental factors to acquire in expertise are motivation and self-confidence, by which athletes manifest their expertise leading to focused performance, refocusing and positive anxiety control [8].

Mental skills are important components for success in major sport competitions [3]. The amount of use of mental skills can be considered as a main factor distinguishing an elite athlete from a sub-elite one. Taking into account the influence of competition environment on athletes' performance and considering the fact that most environmental factors target athletes' mental aspects, the importance of training and measuring the results can be considered one of the coaches' main responsibilities. Sport psychologists have divided mental skills into three main categories [9]: The first category is founding mental skills, including goal setting, self-confidence and commitment. Therefore, it can be claimed that subsequent mental skills will not be influential until such mental skills are stabilized in the athlete [10] [11]. The second category is psychosomatic skills, which include anxiety reactions, fear control, relaxation, and activation. According to Landers and Boutcher (1998) such features deal with athletes' physiological characteristics [12]. The third category is called cognitive skills, which includes imagery, mental practice, focusing, refocusing and competition planning [13].

Recent developments in team and individual sports have heightened the need for coaches' and researchers' knowledge about mental preparation programs for the athletes. Accordingly, Devonport (2006) investigating mental skills in elite kick-boxers found that imagery, positive self-talk, relaxation, focusing, control of emotions and goal setting skills influence success [14]. Some researchers [15] also found that athletes in closed skill sports like gymnastics could better focus and refocus after failure. Similarly, Kruger (2010), comparing mental skills between successful and unsuccessful golf players, concluded that the two groups were different in such skills as acquisition of motivation, anxiety reaction, fear control, self-confidence, and mental imagery [16]. Sotoodeh, Talebi, Hemayattalab, and Arabameri (2012) examined the differences between elite and non-elitetaekwondo athletes and found that non-elite athletes need to improve such skills as competition planning, goal setting, activation, self-confidence, and commitment. They also found that elite athletes need to improve refocusing and anxiety reaction [17]. In another study, Nourbakhsh and Maleki (2005) found a significant difference between elite male athletes in individual and team sports on anxiety reaction and mental training skills [18]. Ghare, Keshtidar and Jahangiri (2009) investigated the difference of mental skills in open and closed sports in athletes and indicated that the two groups differ only in psychosomatic skills [19].

Literature review clearly reveals affective variables related to mental skills, such as experience [1] and clearing up ambiguity for athlete's psychological features in various sports. Studies indicate that athletes' level of experience is strongly related to their amount of use from mental skills. So far, however, there has been little discussion about relationship between individual and team sports, neither the effectiveness of the above factors is proved in case of other contexts where it is possible for such variables to play an important role. In addition, this relationship isn't clear between individual and team sports with different exercise and competition climates. The purpose of this study, therefore, is to find out if there is any difference between elite and sub-elite basketball players and gymnasts in their basic mental skills, psychosomatic skills, and cognitive mental skills.

\section{Methodology}

The present study was a descriptive one. The population in this study included student athletes participating in the $11^{\text {th }}$ nation-wide university sport festival as well as gymnasts taking part in the country's gymnastics championship. From this population, 161 basketball players (91 experienced: aged $22.47 \pm 2.27$, and 70 inexperienced, aged $23.13 \pm 2.2$ ) and 114 gymnasts (66 experienced; aged $22.77 \pm 2.03$ and 48 inexperienced, aged 
$22.79 \pm 2.25$ ). The criterion used in this study to distinguish elite from sub-elite participants was three years of professional experience, that is, athletes who had taken part in the country's sport championship for three or more than three years were considered as elite and those who took part in such sport championships for less than three years were considered as inexperienced.

The questionnaire used for this study was OMSAT-3 that assessed mental skills in three main categories of basic mental skills (goal setting, self-confidence and commitment), psychosomatic skills (stress reaction, fear control, relaxation, and mental activation) and cognitive skills (focusing, refocusing, mental imagery, mental exercise, and competition planning). Internal reliability of the questionnaire was measured by alpha amount ranging from 0.68 to 0.88 and its validity ranging from 0.78 to 0.96 [20]. In another study, Sanati Monfared (2006), working with a number of Iranian athletes in Iran's national championship committee, measured the validity and reliability of the questionnaire as equivalent to $r=0.89$, using test retest method [21]. As a result, analytical results for mental skills $(\mathrm{p}=0.000, \mathrm{df}=63$, AGFI $=0.956$ ) were obtained. To obtain the questionnaire's internal reliability, Cronbach's Alpha was used and the amount of reliability for anxiety scale turned out to be 0.88 . Table 1 indicates the internal reliability of both variables in the questionnaire.

Taking into account the obtained figures for Alpha, it could be claimed that the obtained Alpha is within an acceptable range and measurement tools have acceptable internal reliability. In order to organize, summarize, and categorize the information in this study, the researchers used descriptive methodology and inferential statistics. In order to measure the reliability, MAANOVA was applied to examine the difference between obtained data using SPSS software version 20 and LISREL version 8.57.

\section{Results}

The results of this study indicate are descriptive and prescriptive. Table 1 indicates descriptive results of three mental categories in this study.

In this study, the researcher intends to find out if there is any difference between elite and sub-elite basketball players' and gymnasts' basic mental skills, psychosomatic skills, and cognitive skills. After making sure that the data have been equally distributed by Kolmogrov-Smirnov test $(\mathrm{p}>0.05)$, and after testing co-variance matrix using Box test $(\mathrm{p}<0.05)$, MANOVA test was applied to examine the hypothesis. According to the results of this study, there is a significant difference between elite and sub-elite basketball players and gymnasts in basic mental skills $\left(\mathrm{F}_{3271}=13.3, \mathrm{p}=0.000\right)$, psychosomatic skills $\left(\mathrm{p}=0.000, \mathrm{~F}_{3271}=18.63\right)$ and cognitive skills $\left(\mathrm{F}_{3271}=\right.$ 32.77, $\mathrm{p}=0.000$ ) (Table 2). This means that the more experience in exercise and competition, the more use mental skills.

Since there exists a meaningful difference between all groups' mean according to the results of this study, LSD test was used to identify groups that had meaningful difference with each other (Table 3).

Table 1. Internal reliability figures.

\begin{tabular}{ccc}
\hline Variable & Dimension & Cronbach's alpha \\
\hline \multirow{2}{*}{ Basic mental skills } & Goal setting & 0.77 \\
& Self confidence & 0.77 \\
& commitment & 0.78 \\
Psychometric skills & Stress reaction & 0.79 \\
& Fear control & 0.80 \\
& Relaxation & 0.77 \\
& Mental activation & 0.76 \\
Cognitive skills & Mental imagery & 0.77 \\
& Mental exercise & 0.77 \\
\hline
\end{tabular}


Table 2. Descriptive results of mental skills.

\begin{tabular}{|c|c|c|c|c|c|c|}
\hline Mental skill & Field & Expertise level & Number & Mean & Standard deviation & Mean Standard Error \\
\hline \multirow{4}{*}{ Basic } & \multirow{2}{*}{ Basketball player } & Inexperienced & 70 & 61.65 & 9.1 & 1.15 \\
\hline & & Experienced & 91 & 61.02 & 8.7 & 0.91 \\
\hline & \multirow{2}{*}{ Gymnast } & Inexperienced & 48 & 50.33 & 11.67 & 1.68 \\
\hline & & Experienced & 66 & 58.97 & 12.84 & 1.58 \\
\hline \multirow{4}{*}{ Psychometric } & \multirow{2}{*}{ Basketball player } & Inexperienced & 70 & 67.27 & 6.52 & 0.78 \\
\hline & & Experienced & 91 & 66.48 & 8.31 & 0.87 \\
\hline & \multirow{2}{*}{ Gymnast } & Inexperienced & 48 & 54.66 & 13.52 & 1.95 \\
\hline & & Experienced & 66 & 58.86 & 15.37 & 1.89 \\
\hline \multirow{4}{*}{ Cognitive } & \multirow{2}{*}{ Basketball player } & Inexperienced & 70 & 88.37 & 7.81 & 0.93 \\
\hline & & Experienced & 91 & 89.17 & 9.82 & 1.02 \\
\hline & \multirow{2}{*}{ Gymnast } & Inexperienced & 48 & 70.66 & 12.71 & 1.83 \\
\hline & & Experienced & 66 & 79.93 & 15.81 & 1.94 \\
\hline
\end{tabular}

Table 3. Results of MANOVA test in three categories of basic mental, psychosomatic and cognitive skills.

\begin{tabular}{cccccc}
\hline & Metal skills & $\mathrm{M} \pm \mathrm{SD}$ & $\mathrm{F}_{3271}$ & $\mathrm{p}$ & eta \\
\hline & Basic mental skills & $57.99 \pm 0.65$ & 13.30 & 0.000 & 0.128 \\
Effect of group & psychometric skills & $61.82 \pm 0.68$ & 18.63 & 0.171 & 0.000 \\
& Cognitive skills & $82.03 \pm 0.72$ & 32.77 & 0.266 \\
\hline
\end{tabular}

According to the results of this study, there is a significant difference in basic mental skills among sub-elite gymnasts and basketball players $(p=0.000)$, and among elite and sub-elite gymnasts $(p=0.000)$. There is also significant difference in psychosomatic skills among sub-elite basketball players and gymnasts $(p=0.000)$, elite basketball players and gymnasts $(p=0.000)$, and elite and sub-elite gymnasts $(p=0.000)$. Finally, as it was found in the present study, there is significant difference in cognitive skills among sub-elite basketball players and gymnasts $(\mathrm{p}=0.000)$, elite basketball players and gymnasts $(\mathrm{p}=0.000)$, and elite and sub-elite gymnasts ( $=0.000$ ). This means that experience of different conditions in group and individual sports influences on mental skills. It should be mentioned that no significant difference was found in any of the three categories investigated in this study between elite and sub-elite basketball players. $(\mathrm{p}=0.71, \mathrm{p}=0.65$, and $\mathrm{p}=0.66$ respectively) (Table 4).

\section{Discussion}

The purpose of the current study was to find out if there was any difference in basic mental, psychosomatic and cognitive skills among basketball players and gymnasts with varying levels of experience. The results indicated significant differences between elite and sub-elite basketball players and gymnasts in terms of mental skills.

It was found that there is significant difference among basic mental skills (goal setting, self-confidence, and commitment) between elite and sub-elite gymnasts $(\mathrm{p}<0.05)$. Goal setting [10], self-confidence [8], and commitment [11] are some of the most important factors distinguishing athletes with high levels of performance from those with low-levels of performance. A possible explanation for this is that as the level of experience and expertise of the athlete increases, sport goals become more specialized and challenging, leading athletes toward further success [22]. Professional athletes have, through experience and expertise, realized that better performance requires improvement of reconstructing basic mental techniques, such as goal setting and pre-competition fear control [23]. The findings of the current research are in line with a number of other research studies on athlete mental skills [16] [17] [20] [24] [25].

It was also found that there is a significant difference between psychosomatic skills among elite basketball players and gymnasts $(p<0.05)$. Since there exist differences in a number of conditions such as physical and technical characteristics, amount of athletes' reliance on their abilities and teammate interaction besides anxiety 
Table 4. The result of comparison in four groups in terms of basic mental, psychosomatic, and cognitive skills.

\begin{tabular}{|c|c|c|c|c|c|}
\hline Mental skills & & & Mean & Standard error & $\mathrm{p}$ \\
\hline \multirow{4}{*}{ Basic mental } & \multirow{2}{*}{ Sub-elite basketball player } & Elite basketball player & 0.63 & 1.68 & 0.71 \\
\hline & & Sub-elite gymnast & 11.32 & 1.98 & 0.000 \\
\hline & Elite basketball player & Elite gymnast & 2.05 & 1.71 & 0.23 \\
\hline & Elite gymnast & Sub-elite gymnast & 8.63 & 2 & 0.000 \\
\hline \multirow{4}{*}{ psychometric } & \multirow{2}{*}{ Sub-elite basketball player } & Elite basketball player & 0.78 & 1.76 & 0.65 \\
\hline & & Sub-elite gymnast & 12.6 & 2.07 & 0.000 \\
\hline & Elite basketball player & Elite gymnast & 7.62 & 1.78 & 0.000 \\
\hline & Elite gymnast & Sub-elite gymnast & 4.19 & 2.09 & 0.04 \\
\hline \multirow{4}{*}{ cognitive } & \multirow{2}{*}{ Sub-elite basketball player } & Elite basketball player & -0.8 & 1.85 & 0.66 \\
\hline & & Sub-elite gymnast & 17.7 & 2.18 & 0.000 \\
\hline & Elite basketball player & elite gymnast & 9.23 & 1.88 & 0.000 \\
\hline & Elite gymnast & Sub-elite gymnast & 9.27 & 2.21 & 0.000 \\
\hline
\end{tabular}

and conditions and demand for focus, both in individual and team sports athletes use different mental skills because of different experiences related to these factors [5]. Researchers believe that since individual sports athletes can't rely on their teammates, they are more likely to be threatened by anxiety reactions during the sport competition [4]. Since anxiety reaction is measured by physical response to the demands of the competition environment, it is closely similar to physical anxiety. Anxiety theorists believe that athletes in individual and closed sports have enough time to process physical signals, thus have enough time to negatively react to physical responses. In team and open sports, however, since athletes have more attention and interaction during the sport competition, there is less time for the athletes to think about anxiety signals [26]. This finding is in agreement with literature [18] [19]. Those studies indicated that there exists a significant difference between psychosomatic skills in individual and team sports athletes and athletes in team sports can control anxiety better than individual athletes.

A significant difference was found between psychosomatic skills among elite and sub-elite gymnasts $(\mathrm{p}<$ 0.05). One of the psychosomatic skills serving as an important predictor index of competition anxiety is anxiety reaction [16] [17] [24]. Negative reaction to anxiety can destroy athlete performance. Weinberg and Gould (2007) believe that as the athlete's experience and expertise expands, such factors as being selected for a team, financial concerns, existence of powerful opponents in competitions, media quality, the expectations of the fan for championship, previous sport injuries, and fear from failure affect athletes' performance [1]. His result confirms the researcher hypothesis and was consistent with literature [16] [17] [24], thus athlete's experience and expertise level can influence the type and amount of mental skill usage.

There exists significant difference between elite basketball players and gymnasts in cognitive skills $(p<0.05)$. The kind of mental skill used in team sports is not necessarily similar to those used in individual sports [7]. According to Orlick (1996), the most important factors contributing the success of elite athletes include exercise quality, mental exercise, planning for the competition, focusing and refocusing [11]. In open sport skills where performance environment is permanently changing, to facilitate their performance, athletes try to improve such skills as focusing and refocusing. In closed sport skills, however, where there exists stable condition, improving mental exercise skills are of greater importance than the other skills [19]. Yet, the findings of this study were different from the findings of Ghare et al. (2009). According to their findings, there is no significant difference between cognitive skills of the athletes in team and individual sports. In those study [19] athletes in open sports (basketball, volleyball and wrestling) and closed sports (swimming and track and field) acted differently. In this study, however, the data was collected only from basketball players (open sport) and gymnasts (closed sports). Although the main categorizing index of open and closed sports is stability and instability in the context, the quality and ways of using mental skills for improving performance in sport context has been different and could thus be considered as a reason to this inconsistency.

Also in this study, a meaningful difference was found in the case of cognitive skills between elite and subelite gymnasts $(\mathrm{p}<0.05)$. Like the difference in the case of individual's physical skills, their might also exist 
differences in individual's level of expertise in focusing and forming clean and controlled mental imagery, which is reflected in athletes successful performance at the time of competition. The above issue has been confirmed in literature review. In Walpes's (2003) study, for example, skilled gymnasts were able to focus better than unskilled gymnasts [27]. According to the researchers, successful gymnasts first master basic skills, then turn them to advanced skills; so require more focus. In this way they improve their skills to boost focusing [27]. Neil et al. (2003) investigated the intensity and direction of competition anxiety signals and mental skills use as a function of the level of expertise in rugby players [28]. They indicate that sub-elite athletes often use relaxation techniques to reduce anxiety during the competition, while elite athletes use a combination of skills in order to improve their performance by maintaining intensity levels. There exist close relationship between focus and mental imagery skills, since athletes create mental imagery when they are optimally concentrate and attend on their goals. Mental imagery helps athletes to keep their mental focus during sport competition and gain selfconfidence for peak performance [29]. Vealy (1988) believes that elite athletes are able to master mental imagery, take it under their control, and manipulate it in order to achieve pre-planned goals [30]. In individual sports, such as gymnastics, the athlete's performance is manageable; thus, mental imagery can contribute as the main axis of skills during the performance.

Since less attention is paid to individual sports and because athletes in these fields need more concentration, mental exercise shall be used more in such fields [11]. Moreover, the reconstruction of cognitive skills, such as goal setting and mental imagery for reducing pre-competition anxiety is needed, in order to improve performance [23]. The present study found a meaningful difference between elite and sub-elite gymnast and was thus consistent with the findings of literature [17] [25] [31].

It seems that better understanding and identifying mental skill is crucial in group and individual sports. This finding will help coaches and athletes to improve their performance and consolidate and expand the use of mental skills they need for each competition. However, more research on this topic needs to be undertaken before the association between sport experience level and mental skills is more clearly understood. Thus, further research should be done to investigate the quality and quantity of such mental skills and their degree of influence on improving athletes' performance during exercise and competition, both in the case of elite and sub-elite men and women who are basketball players or gymnasts.

\section{References}

[1] Weinberg, R.S. and Gould, D. (2007) Foundations of Sport and Exercise Psychology. Human Kinetics Publishers, Champaign.

[2] Moritz, S.E., Feltz, D.L., Fahrbach, K.R. and Mack, D.E. (2000) The Relation of Self-Efficacy Measures to Sport Performance: A Meta Analytic Review. Research Quarterly for Exercise and Sports, 71, 280-294. http://dx.doi.org/10.1080/02701367.2000.10608908

[3] Williams, J.M. (2001) Applied Sport Psychology: Personal Growth to Peak Performance. 4th Edition, Mayfield Publishing Company, Mountain View.

[4] Cox, R.H. and Liu, Z. (1993) Psychological Skills: A Cross Cultural Investigation. International Journal of Sport Psychology, 24, 326-334.

[5] Taylor, J. (1996) Intensity Regulation and Athletic Performance. In: Van Raalte, J.L. and Brewer, B.W., Eds., Exploring Sport and Exercise Psychology, American Psychological Association, Washington, DC, 3-24.

[6] Cox, R.H., Liu, Z. and Qiu, Y. (1996) Psychological Skills of Elite Chinese Athletes. International Journal of Sport Psychology, 27, 123-132.

[7] Jones, G. and Hanton, S. (1996) Interpretation of Competitive Anxiety Symptoms and Goal Attainment Expectancies. Journal of Sport \& Exercise Psychology, 18, 144-157.

[8] Williams, J.M. and Krane, V. (2001) Psychological Characteristics of Peak Performance. In: Williams, J.M., Ed., Applied Sport Psychology: Personal Growth to Peak Performance, May Field Publishing Company, Mountain View, 137-144.

[9] Bush, N.D., Salmela, J.H. and Green-Demers, I. (2000) The Ottawa Mental Skills Assessment Tool (OMSAT-3). The Sport Psychologist, 15, 1-19.

[10] Bota, J.D. (1993) Development of the Ottawa Mental Skills Assessment Tool (OMSAT). Unpublished Master Thesis, University of Ottawa, Ottawa.

[11] Orlick, T. (1996) The Wheel of Excellence. Journal of Performance Education, 1, 3-18. 
[12] Landers, D.M. and Boutcher, S.H. (1998) Arousal-Performance Relationships. In: Williams, J.M., Ed., Applied Sport Psychology: Personal Growth to Peak Performance, Mayfield, Mountainview, 197-218.

[13] Meyers, M.C., Bourgeois, A.E., LeUnes, A. and Murray, N.G. (1998) Mood and Psychological Skills of Elite and SubElite Equestrian Athletes. Journal of Sport Behavior, 22, 399-409.

[14] Devonport, T.J. (2006) Perception of the Contribution of Psychology to Success in Elite Kickboxing. Journal of Sport Science and Medicine, 5, 99-107.

[15] Grandjean, D.B., Taylor, A.P. and Weiner, J. (2002) Confidence, Concentration and Competitive Performance of Elite Athletes: A Natural Experiment in Olympic Gymnastics. Journal of Sport and Exercise Psychology, 24, 320-327.

[16] Kruger, A. (2010) Sport Psychological Skills That Discriminate between Successful and Less Successful Female University Field Hockey Players. African Journal for Physical, Health Education, Recreation and Dance, 16, 239-250. http://dx.doi.org/10.4314/ajpherd.v16i2.55963

[17] Sotoodeh, M.S., Talebi, R., Hemayattalab, R. and Arabameri, E. (2012) Comparison of Selected Mental Skills between Elite and Non-Elite Male and Female Taekwondo Athletes. World Journal of Sport Sciences, 6, 32-38.

[18] Nourbakhsh, P. and Maleki, M. (2005) Comparison of Foundation, Psychosomatic and Cognitive Mental Skills between Team and Individual Male Superior Athletes in Khuzestan and Relationship between Those Skills with Self-Efficacy. Harakat, 23, 125-141.

[19] Ghare, M.A., Keshtidar, M. and Jahangiri, M. (2009) Comparison of Mental Skills, Self-Confidence and Competition Anxiety Interpretation among Open and Closed Skills Athletes. Research in Sport Sciences, 25, 49-66.

[20] Durand-Bush, N., Salmela, J.H. and Green-Demers, I. (2001) The Ottawa Mental Skills Assessment Tool (OMSAT-3). The Sport Psychologist, 15, 1-19.

[21] Monfared, S. (2006) Validating OMSAT-3 Questionnaire and Confirming Effect of Mental Preparation Program on Mental Skills at Athletes Participating Asian Games, Doha-Qatar. Iran Olympic National Committee.

[22] Mallett, C.J. and Hanrahan, S.J. (2004) Elite Athletes: Why Does the "Fire” Burn So Brightly? Psychology of Sport and Exercise, 5, 183-200. http://dx.doi.org/10.1016/S1469-0292(02)00043-2

[23] Fletcher, D. and Hanton, S. (2001) The Relationship between Psychological Skill Usage and Competitive Anxiety Responses. Psychology of Sport and Exercise, 2, 89-101. http://dx.doi.org/10.1016/S1469-0292(00)00014-5

[24] Craciun, M., Dobosi, S., Popioan, N. and Prodea, C. (2011) A Confirmatory Factor Analysis of the Ottawa Mental Skills Assessment Tool (OMSAT-3*)_Romanian Version. Human Movement, 12, 159-164. http://dx.doi.org/10.2478/v10038-011-0014-x

[25] Stevenson, M. (1999) The Use of Mental Skills by Male and Female Athletes. UMI, Ann Arbor.

[26] Hardy, L. and Jones, G. (1990) Future Directions for Research into Anxiety in Sport. In: Jones, G. and Hardy, L., Eds., Anxiety and Performance in Sport, Wiley, Chichester, 281-290.

[27] Walpes, S. (2003) Psychological Characteristics of Elite and Non-Elite Level Gymnasts. Doctoral Thesis, Washington State University, Washington DC.

[28] Neil, R., Mellalieu, D.S. and Hanton, S. (2006) Psychological Skills Usage and the Competitive Anxiety Response as a Function of Skill Level in Rugby Union. Journal of Sport Science and Medicine, 5, 415-423.

[29] Martens, R. (1987) Coaches Guide to Sport Psychology. Human Kinetics, Champaign.

[30] Vealy, R.S. (1988) Future Directions in Psychological Skills Training. The Sport Psychologist, 2, 318-336.

[31] Jafari, A., Moradi, M.A. and Rafeenia, P. (2007) Comparison Some of Mental Skills between Female Superior and Inferior Taekwondo Athletes. Olympic, 1, 113-123. 